\title{
A conceptual and empirical framework for the social distribution of cognition: The case of memory
}

\author{
Action editor: Leslie Marsh \\ Amanda J. Barnier ${ }^{\mathrm{a}, *}$, John Sutton ${ }^{\mathrm{b}}$, Celia B. Harris ${ }^{\mathrm{a}}$, Robert A. Wilson ${ }^{\mathrm{c}}$ \\ a Macquarie Centre for Cognitive Science, Macquarie University, Sydney, NSW 2109, Australia \\ ${ }^{\mathrm{b}}$ Department of Philosophy, Macquarie University, Sydney, NSW 2109, Australia \\ ${ }^{\mathrm{c}}$ University of Alberta, Edmonton, Canada \\ Received 4 April 2007; accepted 5 July 2007 \\ Available online 15 August 2007
}

\begin{abstract}
In this paper, we aim to show that the framework of embedded, distributed, or extended cognition offers new perspectives on social cognition by applying it to one specific domain: the psychology of memory. In making our case, first we specify some key social dimensions of cognitive distribution and some basic distinctions between memory cases, and then describe stronger and weaker versions of distributed remembering in the general distributed cognition framework. Next, we examine studies of social influences on memory in cognitive psychology, and identify the valuable concepts and methods to be extended and embedded in our framework; we focus in particular on three related paradigms: transactive memory, collaborative recall, and social contagion. Finally, we sketch our own early studies of individual and group memory developed within our framework of distributed cognition, on social contagion of autobiographical memories, collaborative flashbulb memories, and memories of high school at a high school reunion. We see two reciprocal benefits of this conceptual and empirical framework to social memory phenomena: that ideas about distributed cognition can be honed against and tested with the help of sophisticated methods in the social-cognitive psychology of memory; and conversely, that a range of social memory phenomena that are as yet poorly understood can be approached afresh with theoretically motivated extensions of existing empirical paradigms.
\end{abstract}

(C) 2007 Elsevier B.V. All rights reserved.

Keywords: Distributed cognition; Memory; Autobiographical memory; Transactive memory; Collaborative recall; Social contagion

\section{Introduction}

Paradigms in which human cognition is conceptualised as "embedded", "distributed", or "extended" have arisen in different areas of the cognitive sciences in the past 20 years. These paradigms share the idea that human cognitive processing is sometimes, perhaps even typically, hybrid in character: it spans not only the embodied brain and central nervous system, but also the environment with its social or technological resources (Clark, 1997, 2007; Haugeland, 1998; Hollan, Hutchins, \& Kirsh, 2000; Hutch-

\footnotetext{
* Corresponding author.

E-mail address: abarnier@maccs.mq.edu.au (A.J. Barnier).
}

ins, 1995, 2006; Kirsh, 1996, 2000, 2006; Norman, 1993; Sutton, in press-a; Wilson, 1994). Such views of cognition share a scepticism about the adequacy of conceptualizing cognition as a process that begins and ends at the skull.

One motivation for adopting a perspective in which cognition is embedded, distributed, or extended begins with reflection on the fact that neural systems do not operate in causal isolation from their environments. Moreover, the nature and level of causal integration across the divide between individual and environment suggests that cognitive systems themselves often involve the coupling of neural, bodily, and external systems in complex webs of continuous reciprocal causation. Through evolution and ontogenetic development we have gained capacities skilfully 
to hook up with or incorporate external physical and cultural resources that over time have themselves become apt for incorporation into more encompassing, extended cognitive systems. In this way, we form temporarily integrated larger cognitive units that incorporate distinct but complementary inner and outer components, often making "the world smart so that we can be dumb in peace" (Clark, 1997, p. 180). Embodied human minds extend into a vast and uneven world of things - artefacts, technologies, and institutions - which they have collectively constructed and maintained through cultural and individual history.

Often-cited examples of distributed cognition include studies of the instruments and procedures involved in navigation; the physical objects and epistemic tools used in processing orders in a café; the tangle of notes and records with which an academic paper is written; the way skilled bartenders employ unique glasses to remember cocktail orders; or the sketchpads without which abstract artists cannot iteratively re-imagine and create an artwork (Beach, 1988; Clark, 1997, 2001; Hutchins, 1995; Kirsh, 2006; van Leeuwen, Verstijnen, \& Hekkert, 1999). Developing research programmes in distributed cognition and the extended mind are being tested and applied in disciplines ranging from science studies (Giere, 2002) to cognitive archaeology (Knappett, 2005), computer-supported cooperative work (Halverson, 2002), and Shakespeare studies (Tribble, 2005). Philosophical defenses of the extended mind (Clark \& Chalmers, 1998; Rowlands, 1999; Wilson, 2004) have generated a robust, critical, ongoing debate about the conceptual foundations of the approach (Adams \& Aizawa, 2001, 2007; Clark, in press; Menary, 2006; Rupert, 2004).

This literature on "the cognitive life of things" (Sutton, 2002a) has fuelled a rather technophilic style in distributed cognition research, occasionally resulting in a preoccupation with technology to the relative neglect of social systems (Clark, 2003; Clark \& Chalmers, 1998). Yet in most complex real-world contexts, distributed cognitive processes involve the skilful interactive simultaneous coordination of things and people. One natural strategy to address the methodological challenges this poses is to seek insight from and integration with research traditions that focus on interpersonal interaction in cognition. This is to draw attention to the social aspects of distributed cognitive processes, to cases in which other people - rather than artefacts - are the more-or-less enduring partners in coupled or transactive distributed cognitive systems.

In this paper we thus aim to show that the distributed cognition framework offers new perspectives on social cognition by applying it to one specific domain: the psychology of memory (see also Tollefsen, 2006). In particular, we argue that independent lines of research on memoryabout relations between individual memory and social groups - can be better understood and developed by reconceiving them within this theoretical framework. This focus on the social distribution of cognition is particularly appropriate in thinking about memory, since encoding, storage, and retrieval in real-world contexts all frequently involve the cognitive activities of more than a single individual. This integrative project should have benefits both ways. On the one hand, ideas about distributed cognition can be honed against and tested with the help of sophisticated methods in the social-cognitive psychology of memory; conversely, a range of social memory phenomena that are as yet poorly understood can be approached afresh with theoretically motivated extensions of existing empirical paradigms.

The empirical work on transactive and collaborative remembering that we survey below covers just one of a number of fields to which the framework of distributed and extended cognition can be brought to bear: we could also refer to studies of multi-agent interaction in AI (Koning \& Ling, 2003), small-group research in social psychology (Fiske \& Goodwin, 1994), or (closer to our concern with memory) the flourishing social-interactionist tradition in the developmental psychology of autobiographical memory. In this last field, for example, 20 years of research has built up a rich picture of early personal memory capacities emerging from the dynamical interaction of distinct components in a social-cultural-cognitive-neural system (Nelson \& Fivush, 2004), where the relative influence of multiple concurrent processes can vary across cases (Griffiths \& Stotz, 2000; Reese, 2002; Smith \& Thelen, 2003; Sutton, 2002b). Early joint attention to the past between carers and children slowly helps the child achieve a grasp of the causal significance of the order of events, of the availability of distinct perspectives on the same past time, of the uniqueness of actions, and of the affective and social significance of the sharing of memories (Campbell, in press; Hoerl \& McCormack, 2005). Independent work on children's explanatory knowledge, and particularly on their knowledge about the social division of cognitive labour (Lutz \& Keil, 2002; Rozenblit \& Keil, 2002; Wilson \& Keil, 2000 ), is also relevant here. While we will not discuss this developmental work further in this paper, the picture of early personal memory as socially distributed clearly dovetails with the view of the cognitive psychology of memory that we offer below.

The conceptual and empirical benefits that flow from this exploration of the social distribution of memory might also include the forging of new multidisciplinary middleground for memory studies. While mainstream philosophy of mind has largely neglected social aspects of remembering, studies of "collective memory" and "cultural memory" abound in a burgeoning interdisciplinary field spanning sociology, anthropology, history, political theory, and media theory (Bloch, 1998; Kansteiner, 2002; Klein, 2000; Olick, 1999; Wertsch, 2002). We think that such social memory studies are potentially relevant for cognitive science and philosophy, and believe that both psychologists and humanities scholars can contribute directly to better understandings of the relations between broader studies of national or cultural memory and the typical individual or small-group focus of cognitive psychology with its 
empirical methods (Sutton, 2004, Suttonin press-b; Wilson, 2005a). Since the phenomena in question in social memory studies do not recognize disciplinary boundaries, it is particularly important to seek both conceptual clarity on key terms and effective shareable methods (see also Hirst \& Manier, in press).

In the next section we flesh out the kind of memory phenomena in which we are particularly interested. We specify some of the key social dimensions of cognitive distribution, and some of the basic distinctions between cases that our psychological studies need to respect and investigate. We also briefly show how our approach to distributed remembering can be interpreted within stronger or weaker versions of the general distributed cognition framework. Then in Section 3 we examine studies of social influences on memory in cognitive psychology, identifying the valuable concepts and methods to be extended and embedded in our framework. Here we focus in particular on three related paradigms: transactive memory, collaborative recall, and social contagion. In Section 4 we sketch our own early studies of individual and social memory developed with the framework of distributed cognition in mind.

\section{Memory as a test case for distributed cognition}

\subsection{Autobiographical memory and external influence}

While remembering past experience is an activity of intense personal significance, the functions and expressions of autobiographical memory are, equally obviously, deeply embedded in our social world, in adult life as well as childhood. Recollecting specific episodes from the personal past can play many different cognitive, emotional, and interpersonal roles. Alongside the importance of forging, maintaining, and sharing an accurate grasp of past events, the activity of remembering itself keeps the past alive for a variety of present purposes, which is one reason why the qualitative and affective tone of our memories is often entangled and renegotiated in our practical reasoning over time. For example, autobiographical memory shapes and in turn is shaped by our self-conceptions: my decision-making, my choices, and my values are driven in part by the content of ongoing activities of remembering which have themselves been sculpted in part by my working selves, with their goals and their motivations (Barnier et al., 2007; Barnier, Hung, \& Conway, 2004; Conway, 2005; Nelson, 2003). We also rely on personal memory to teach or inform others, to develop and maintain intimacy, to elicit or show empathy, and to share mundane or significant stories. In short, autobiographical memory is not simply about accurately recalling episodes from one's past; it is also enmeshed in our broader ongoing cognitive lives.

In general, we live these cognitive lives, and engage in the activities that constitute them, in the company of others. Our experiences, especially our significant experiences, are often joint experiences with others of importance to us, such as friends and family. And when our experiences have not been shared by family or friends, we often relate those experiences to them. Sometimes we learn (often to our delight or relief, sometimes to our dismay) that others have had similar experiences. And when we have experienced something alongside other people-for example, when a group of us went through some phase of life together as a cohort, or when we have deliberately engaged in a course of joint action-our later accountings and attempts to understand "how it went" can be of great emotional importance for both individuals and the enduring group. In the strongest such cases, long-standing groups return often to rethink or talk through the same shared past events and experiences, perhaps reevaluating their lives or their relationships in part on the basis of, or by way of, reinterpretations of the shared past. Significant reconsideration and redirection of values and plans can be not only triggered by but also enacted in renegotiation of some still-live past.

But in more mundane cases too, as Campbell (in press) puts it, "sharing memory is our default" (p. 4). Even those occasions when we are silent about our pasts "have some of their meaning in relation to our natural habit of sharing the past" (p. 4). How much does this fact matter? What does it imply about the nature of autobiographical memory? And does it suggest that there is room for a social ontology of memory, as there may be for intention, belief, or action (Gilbert, 1989; Searle, 2006; Velleman, 1997), or for empirical research into memory in social groups? On many dominant views in both philosophy of mind and cognitive psychology, the sharing of memories is only of limited significance. The presence and contribution of other people as real or imagined participants in activities of remembering is seen, at best, as only one external causal trigger for and influence on the real memory processes in the individual; or, at worst, as a disrupting or contaminating influence on individual autobiographical memory.

In the powerful tradition of cognitive psychological work on false memory, for example, evidence for the constructive nature of remembering is typically interpreted in an individualist fashion. Elizabeth Loftus writes, for example, that "misinformation has the potential for invading our memories when we talk to other people" (Loftus, 1997, p. 51). Construction is equated with distortion, thus minimizing the adaptability of memory's intrinsic dynamics, by which the very mechanisms that underlie generalization can in certain circumstances lead us astray (McClelland, 1995; Schacter, 1999). And external influence is typically characterized as primarily negative, the relentless intrusion of the social into malleable individual memory. Such views fail to do justice to the extraordinary diversity of social memory phenomena, especially to the ways in which sharing our past can facilitate our access to it and our capacity to negotiate its legacies. Truth, and related values like accuracy and fidelity in memory, need be neither simple nor singular: ordinary and successful remembering, far from being inevitably compromised and corrupted by other people, may be "relational", depending 
directly on the support and uptake of other people (Campbell, 2003, 2006).

A more nuanced picture of the complex and often positive roles of external social influence in remembering need not, however, remain distant from the best work in cognitive science. The versions of distributed cognition and extended mind hypotheses on which we draw are entirely compatible with computational and representational theories of mind (Rowlands, 1999; Wilson, 1994, 1995, 2004). Computational efficacy is often enhanced by allowing information to remain outside the brain, and by thus exploiting environmental and social resources rather than having to encode everything relevant internally. A robust integration of the social sciences of memory with the cognitive sciences in this area will require better conceptual resources, empirical methods, and more precise distinctions which align with (even if they do not mimic) the central distinctions between modes and kinds of memory developed in cognitive psychology. The experimental work described below is a natural extension of existing ways of studying the episodic and autobiographical forms of long-term declarative memory. Investigations into other forms of memory may also be of considerable interest, going beyond the "collected memory" (Olick, 1999) approach that views the memories of groups summatively (e.g., Schwartz \& Schuman, 2005). To convey a better sense of the spaces of possibilities for research on the social distribution of memory, we need to be explicit about some of the dimensions to that space.

\subsection{Dimensions of distribution in remembering}

On the distributed cognition view, remembering agents may gain new capacities when they hook up and coordinate with, or rely on specific other people or resources, or when trained with particular learned techniques. We can examine such distributed memory systems and identify the dimensions on which they vary. For example, some distributed memory systems may be little more than aggregates of individual rememberers, while others involve collective agents as truly emergent entities (Poirier \& Chicoisne, 2006; Wimsatt, 1986). In other words, in some cases it is appropriate simply to sum individual memories, for instance those of a bunch of strangers who happened to witness the same accident. But in other cases - if, for example, these witnesses later discuss or debate intensely the details of the accident among themselves - the account of the past which emerges may differ significantly from such an additive mere juxtaposition of individual memories. This is the strategy we want to deploy: refining a theory with a range of specified dimensions on which individual cases can vary, and simultaneously refining our empirical methods for working out just where on each dimension the cases fall. In the case of social interactivity, as our development of the notion of collaborative recall will show, there are many different group contexts of recall, and many different ways in which the short- or longer-term outcome of social interaction can be something quite other than the mere sum of pre-existing individual memories.

We should expect no general answer to the question of whether social effects bring greater or lesser accuracy, qualitatively richer or thinner memories, more or less agreement, or more or less confidence. These are all independent dimensions that have to be teased apart for each kind of interaction, because different forms of collaboration have different costs and benefits, different functions, and different effects on the subsequent fate of the memories which each individual takes away from the interaction with others. The most fruitful approach, in our view, is one that seeks to articulate the conceptual and empirical space in which socially distributed memory can be explored. The initial empirical studies reported in Section 4 begin to do so: here we set out more explicitly some of the dimensions of this space.

As we have already suggested, we can distinguish between experiences that are in some way held in common, jointly experienced at the time of encoding, and those that are not. There are then further distinctions among varieties of such unshared and shared experiences. Some of the experiences that we do not share are nonetheless similar, such as common, major events in high school (final exams, graduation dance), while others are entirely unique to each of us. And of those that are shared with others (at encoding), some are merely accidentally shared, as when we all hear separately about some news item of general public interest, while others are shared because we acted together, as (for example) a tightly knit group over our last year at school. Again, turning our attention to retrieval, remembering can be done in isolation (in various ways and for various purposes), or under a range of increasingly collaborative conditions with other people. Even unshared experiences can be remembered collaboratively with some particular audience or interlocutors, when others play some part (helpful or intrusive, supporting or misinforming) in the processes of recall; while shared experiences can be remembered in company in merely minimal ways, such as when we all just take turns to remember parts of the past, or in more transactive and interactive fashion, when we are jointly involved in a collective project of revisiting and reevaluating what we once went through together. Collaboration takes many forms, and can be supportive of good remembering as well as a source of distortion.

In effect, this is to claim that there is no single characterization of what it is either to "share an experience" or to "collaboratively recall", since these will vary along the dimensions we have specified. The same is true of what it is to be a member of a social group, a question usefully informed by recent work in both social theory and the philosophy of biology. Margaret Gilbert, for example, argues that even a fairly transitory collectivity can form a genuinely plural subject-potentially the subject of memories as well as intentions, beliefs, and actions - as long as its members pool their wills and share certain forms of common knowledge of their mutual awareness (Gilbert, 1989, 
2003). Philip Pettit, in contrast, requires a genuinely integrated collectivity to have more enduring mechanisms of self-regulation, so as to be (for example) answerable as a group to its past actions and judgements (List, in press; Pettit, 2003; Pettit \& Schweikard, 2006). Meanwhile, the revival of work on group selection in the philosophy of biology has reinvigorated discussion of what groups need to be like in order to be "units of selection" and, more generally, causal agents in the process of natural selection (Okasha, 2007; Sober \& Wilson, 1998; Sterelny, 1996; Wilson, 2005b, 2007).

So understanding the nature of the group matters in the study of social memory phenomena both in relation to the experiences encoded, and in identifying particular forms of collaboration in recall. Some distributed systems are oneoffs, establishing transient and easily dissoluble relations, which may yet exhibit high degrees of emergence: as we noted, people who have been thrown together by chance, for example, in witnessing the same accident or being together when they hear of a public figure's death, may find their memories strongly linked in and by discussion of this incident alone. But in other cases we can identify transient but regularly repeatable integrated groupings of people who come together in thinking and talking about the past for a range of present purposes. The narratives revisited in the context of the family unit, or among a tightly knit group of colleagues or old allies, have their own familiar flavour, both constrained and enabled by the ongoing uptake and interests of the various interlocutors. The stories of the shared past, of the events that we remember, are continually renegotiated as we improvise and riff around them with more or less control, and thus they come to have their own autonomy and integrity and internal tensions and lacunae.

From the point of view of theories of distributed cognition, here we are studying "the durability and reliability of the extended cognitive system that results from the functional integration" of distinct resources (Wilson \& Clark, in press). We aim at richer taxonomies which allow us to identify variously stronger cases of collaborative remembering of shared experiences. From this perspective, the "extended mind" label naturally marks not a metaphysically distinct set of cognitive systems, but simply those which score more highly on these dimensions of durability and reliability, and in which the new capacities of the coupled system are "sufficiently robust and enduring as to contribute to the persisting cognitive profile" of an individual (Wilson \& Clark, in press). As the work on transactive memory described below suggests, socially distributed memory systems will often be more efficient and more appealing if they are more enduring: a partner or a lifelong friend holds more of my past, and can often help me negotiate it more appropriately, than a new acquaintance.

By using the inclusive labels "social memory phenomena" and "collaborative remembering" here, we intend not only to mark out the space for such multidimensional enquiry, but also explicitly to resist the urge towards an agreed advance definition of "collective memory". "Collective memory", whatever it may be, is unlikely to differ from individual memory on just one criterion. We need to map, both conceptually and empirically, a range of increasingly strong cases before we decide whether we have found anything worthy of such a label. By acknowledging the reality of many weaker cases, in which (for example) unshared experiences are remembered in one of many less interactive ways, we make room for stronger cases that score more highly on more of the dimensions of distribution we have sketched.

With this in mind, and adapting an earlier discussion of the group mind hypothesis in the biological and social sciences (Wilson, 2004, 2005b), we now consider in turn three different theses that might direct research on social memory phenomena:

- The Triggering Thesis: remembering is a cognitive process that takes place inside individuals, although it can be initiated, at either the encoding or the retrieval phase, by social phenomena.

The Triggering Thesis may be true of some activities of remembering. But it has also come to play a global, structuring role in how many cognitive scientists and philosophers think about the place of "the social" in memory. In fact, many cognitive psychologists in particular would take the Triggering Thesis to provide an exhaustive, capsule statement of the way to conceptualise the role of social phenomena in the process of memory. On this view, social phenomena are merely external contexts, triggers or inputs to in-the-head remembering. We suggest that this view, construed as a global view about social memory phenomena, is mistaken. Although the Triggering Thesis may provide an appropriate background assumption for some investigations of social influences on memory, we illustrate below our reasons for thinking that our empirical and conceptual frameworks need to go beyond this thesis in order to do justice to the full range of social memory phenomena.

- The Social Manifestation Thesis: remembering is a cognitive process that can only be manifested or realized when the individuals engaged in that process form part of a social group of a certain kind.

While the Social Manifestation Thesis shares with the Triggering Thesis a view of remembering as an individual-level process, a process whereby it is individuals who are the agents of acts of remembering, these two theses differ in terms of whether they view memory as an individual-bound phenomenon or one that crosses the bodily boundary. The Social Manifestation Thesis could be read as saying that remembering is essentially social in that it is only individuals in groups (of certain kinds) who remember. But just as we believe that the Triggering Thesis is wrong if understood as a global claim about the essence or nature of memory in general, so we prefer a more 
modest reading of the Social Manifestation Thesis: we recommend understanding of this thesis as saying that certain kinds or episodes of remembering are social in that only individuals in groups (of certain kinds) remember in these characteristic ways. This is the view which operates as background to our discussion of empirical studies of social memory phenomena in the rest of this paper.

- The Group Mind Thesis: remembering is a cognitive process that groups themselves, rather than the individuals that compose those groups, engage in.

The Group Mind Thesis contrasts importantly with the other two theses, in suggesting that remembering is actually a group-level phenomenon, one where it is groups that are the agents of memory. Like the Social Manifestation Thesis, it will seem wildly implausible to cognitive scientists, especially psychologists, if read as making global, essentialist claims about memory. We concur, although we will not be defending or exploring the Group Mind Thesis here: but we again note that this is not how the Group Mind Thesis should be understood, when considered as part of an attempt to broaden the space of possibilities for studying the social distribution of memory. Either the Social Manifestation Thesis or the Group Mind Thesis may be right about the nature of certain types of remembering, even if neither has any prima facie plausibility when regarded as views of memory in general. Precisely the same, as we noted above, is true of the Triggering Thesis. Once the three theses have been redescribed in the ways we recommend, as potentially applying only to certain kinds or episodes of remembering, they are compatible (at least potentially) rather than in conflict. We do not then have to make a once-and-for-all theoretical decision about which of the three is true: in principle at least, each might be true of different phenomena which could all be explored empirically.

Although we do see the Group Mind Thesis, in certain forms, as worthy of further clarification and reconsideration, we have nothing more to say about it here, save to point out that it is independent of the Social Manifestation Thesis. But we do think that the Social Manifestation Thesis expresses an important truth about a range of social memory phenomena. Although the methodological and conceptual amendments to existing psychological paradigms which we suggest below do not yet take us far towards a demonstration of its scope, which would require more thorough empirical exploration of the space of possibilities in question, they do point towards some of the types of remembering which are socially manifested.

\section{An empirical framework}

In this section we review studies on social influences on memory from cognitive psychology. We focus in particular on research that has sought to explore the relationship between individual memory, individual memory in small groups, and some notion of small-group "collective" memory. The purpose of this review is to identify the valuable concepts and methods from three research traditions: transactive memory, collaborative recall and social contagion, which can be extended and embedded in our application of the distributed cognition framework to autobiographical memory. Each of these traditions has its own assumptions about the differences between remembering alone and remembering in a group, each has its own way of measuring this group influence, and each focuses on certain kinds of groups and certain kinds of memories (see also Harris, Paterson, \& Kemp, in press). Although each has been explored primarily against the theoretical backdrop summarized by the Triggering Thesis, we think that research in each tradition can be profitably reconceptualized and extended under the umbrella provided by the Social Manifestation Thesis.

\subsection{Transactive memory}

According to Wegner (1987) and Wegner, Giuliano, and Hertel (1985), transactive memory is a "set of individual memory systems in combination with the communication that takes place between individuals" (Wegner, 1987, p. 186). That is, transactive memory involves the sharing across individuals within certain kinds of relationships or social groups of the encoding, storage and retrieval of individual memory. Wegner's theory is important because, in comparison to more individualistic theories, it captures a truly shared memory system and speaks to the kinds of social memory phenomena that we are most interested in. However, his theory has failed to generate broad empirical attention and has mainly been tested in applied, organisational settings and with non-autobiographical stimuli.

Transactive memory theory predicts that memories recalled by the individuals in the transactive system will be more than the sum of individual memory. That is, transactive memory systems should have emergent properties (properties which differ from the mere sum of the properties of their parts), either in terms of the amount of information recalled or the quality of that information. For instance, Wegner et al. (1985) described a couple discussing a shared party experience. The male partner says that he noticed that a male friend of theirs ("Tex") was depressed and hardly talked, while the female comments that earlier in the evening Tex seemed over friendly. This prompts the male partner to remember a previous occasion where Tex mentioned he was thinking of splitting from his wife. Together, the couple concludes that Tex was flirting with the female partner and was embarrassed about it when he encountered the male partner. This version (regardless of its accuracy) will now become their memory of the events, and it is quantitatively and qualitatively different from what each remembered alone.

Transactive systems might be possible amongst casual acquaintances, people thrown together by chance, or strangers, since individuals routinely make assumptions 
about the expertise of others based on factors such as their age, race, gender, or profession. However, the most efficient systems are likely to develop over time among people who repeatedly remember together, such as couples, families or colleagues (Wegner et al., 1985; see also Tollefsen, 2006) since communication is the key to an efficient transactive system (Hollingshead, 1998a). People in close relationships have information that each alone is responsible for knowing (differentiated, non-redundant information), as well as information that is shared by all members of the group, whether between a couple or among a family (integrated, redundant information). Wegner argued that a successful relationship requires some differentiation of information, for the sake of efficiency, but also some integration of information, or "common knowledge". Differentiation means that the group, as a unit, can store and access more information than the individuals could alone. Integration means that the group can produce new information, since group members can cue each other to produce more information about that topic than they each would alone (for more on redundancy and information sharing see Ohtsubo, 2005; Tindale \& Sheffey, 2002).

In a typical transactive memory experiment, individuals are paired with someone they know (e.g. intimate partner, co-worker) or with a stranger to complete a memory task that involves learning and recalling information in different knowledge areas (e.g. science, sport, history, etc.). Participants rate the extent to which they believe that they and the (known or unknown) person they are paired with know about each category, and are told that they will be remembering with the person they are paired with, and that their responses will be pooled. They then learn information individually and, subsequently, recall with the other person (see Fig. 1).

The limited work conducted so far has shown that people in long-term relationships perform better on these cat- egorised memory tasks than pairs of individuals (Wegner, Erber, \& Raymond, 1991). However, this advantage is only apparent when pairs are allowed to use their own structure at learning; pairs of strangers perform better when structure is imposed (Wegner et al., 1991). Interestingly, collaboration during learning (rather than only during recall) impairs the recall of couples compared to strangers. Hollingshead (1998b) found that couples who learned alone but collaborated at recall performed better than pairs of strangers. However, when the groups collaborated at learning as well as at retrieval, pairs of strangers performed better than couples (Hollingshead, 1998b). Hollingshead (1998b) argued that the attempt to discuss and develop explicit learning strategies impeded the couple by encouraging them to depart from their usual implicit, transactive system.

Transactive memory experiments have mainly used simple stimuli, such as knowledge pooling tasks or categorised word lists. So far, little research has examined transactive systems for the kinds of information that a couple or family may encounter daily, such as performing household tasks or remembering autobiographical events. Applied organisational research has tended to focus on group task performance, such as assembling a radio (Ren, Carley, \& Argote, 2006) or more ecologically valid performance measures of fulfilling company objectives (Austin, 2003), but everyday social applications of transactive memory generally have not been explored. Despite this limitation and unlike many other cognitive memory paradigms, experiments on transactive memory consider what happens in real, established groups. And unlike other cognitive paradigms that see social influence only in terms of contamination or misinformation, transactive memory assumes that group memory can be positive; Wegner's theory focuses on the functional and adaptive nature of sharing memory work in stable groups.

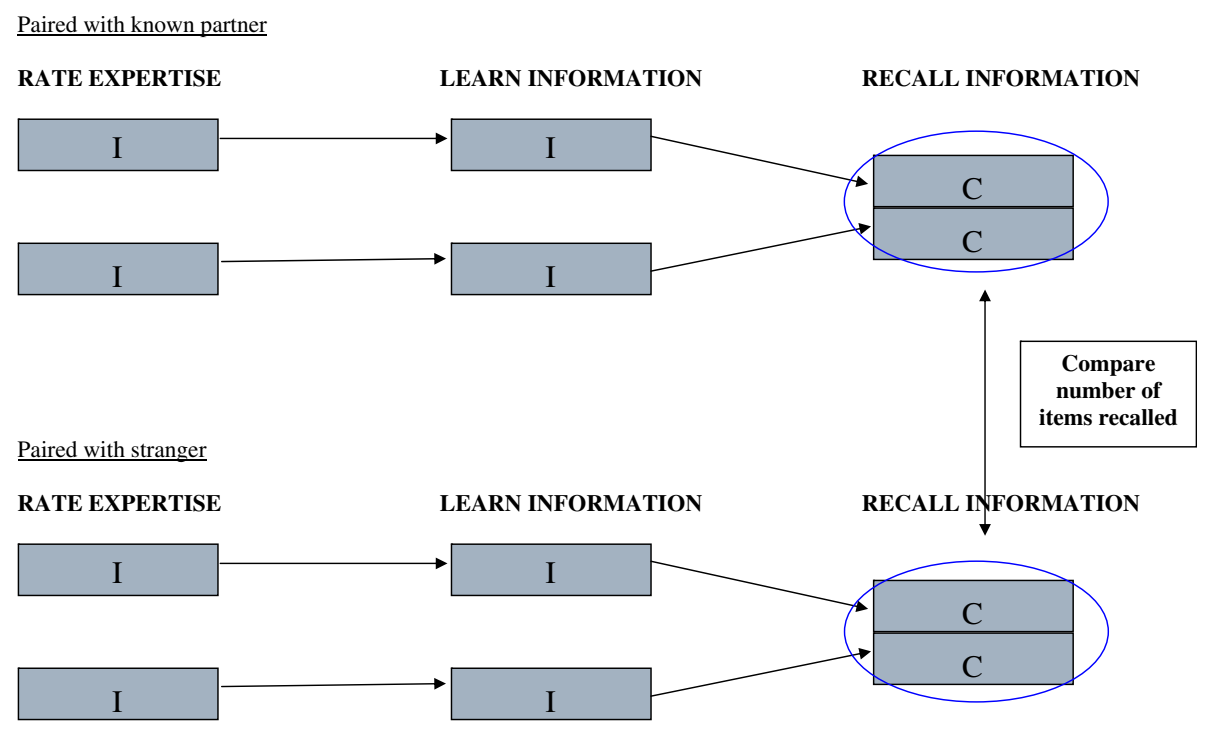

Fig. 1. Transactive memory procedure. 


\subsection{Collaborative recall}

In a typical collaborative recall experiment, participants are presented with stimuli (usually words) on a computer screen and instructed to remember them. Subsequently, participants recall these words either individually or in a group (recall 1). Finally, all participants recall individually again (recall 2). The effect of collaboration on recall is indexed by a (between groups) comparison between the number of items recalled by individuals alone and groups on recall 1 , as well as between the number of items recalled by collaborative groups and nominal groups. Nominal group recall is calculated by pooling the non-overlapping items recalled by the same number of individuals as in the collaborating group, but recalling alone. For example, imagine there are three participants in each group. Nominal group recall would be taken by pooling the recall of sets of three participants who recalled individually. If participant 1 recalls items $A$, $\mathrm{B}, \mathrm{C}, \mathrm{D}$, participant 2 recalls items $\mathrm{A}, \mathrm{D}, \mathrm{F}$, and participant 3 recalls items $\mathrm{B}, \mathrm{C}, \mathrm{G}, \mathrm{H}$, the pooled non-overlapping recall is items $A, B, C, D, F, G$ and $H$. This is then compared to collaborative group recall to index the effects of collaboration on items remembered vs. forgotten (see Fig. 2).

The effects of collaboration on recall can be conceptualised in terms of costs and benefits (Basden, Basden, \& Henry, 2000). Typically, collaborative groups recall more than individuals alone, but less than nominal groups. This deficit is termed collaborative inhibition. However on subse- quent individual recall, those who previously recalled in a group are more likely to remember additional items than those who recalled individually, but only those items that were introduced by another group member. People who recall in groups are less likely to recall items that did not appear in the group recall (Basden et al., 2000). The focus of these comparisons is on the amount of information recalled.

Although the collaborative recall procedure was introduced by Weldon and Bellinger (1997) as a measure of "collective memory" and the emergent properties of group memory - the title of their paper was "Collective memory: Collaborative and individual processes in remembering" - the most commonly cited explanation for collaborative inhibition focuses on individual rather than group processes. Basden, Basden, Bryber, and Thomas (1997) argued that recalling information in a group setting interrupts people's individual retrieval strategies, making them less efficient. This hypothesis was supported by a series of experiments that manipulated interruption of retrieval strategies (Basden et al., 1997; Finlay, Hitch, \& Meudell, 2000; Wright \& Klummp, 2004). Across these studies, researchers essentially treat social processes and the social context as analogous to any other (withinthe-head) disruption of recall strategy.

The exact procedure used across studies has varied greatly, and while some of these variations may be important in understanding collaborative recall, their effects have not been systematically tested. One set of important variations has been the nature of the group:

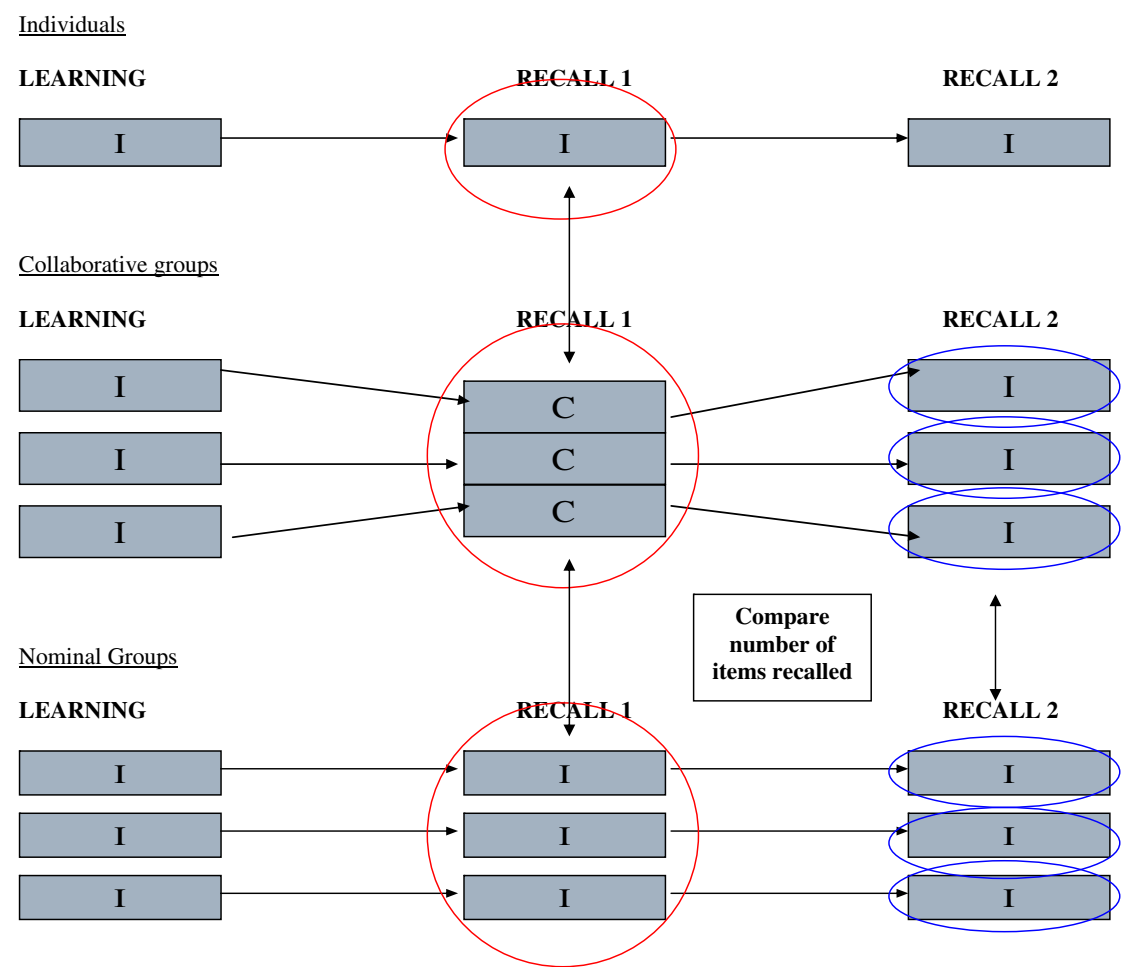

Fig. 2. Collaborative recall procedure. 
their collaboration, their size and make-up, and their dynamics. Given our comments above, this dimension is crucial. For example, group recall in collaborative recall experiments has either consisted of non-interactive collaboration, "turn-taking" (e.g., Basden et al., 2000), or more genuinely interactive collaboration, reaching a consensus (e.g., Finlay et al., 2000). Other research has compared collaborative recall in groups of acquaintances and groups of strangers, with mixed results. Anderson and Ronnberg (1995) reported less collaborative inhibition in groups of friends, while Gould, Osborn, Krein, and Mortenson (2002) reported no difference between married and unacquainted dyads. Most recently, Cuc, Ozuru, Manier, and Hirst (2006) examined the effects of group dynamics (specifically, a dominant narrator) on the collaborative recall of stories by families. Families with a dominant narrator were more likely to develop "collective" or convergent memories than families with more egalitarian conversational dynamics. These findings indicate that the type of collaboration, the nature of the group, and the roles adopted by group members during collaboration may all be crucial predictors of group memory performance.

Another important feature of real-world social remembering is that it usually occurs for personal and potentially emotional and significant autobiographical events. In the first study of its kind, Yaron-Antar and Nachson (2006) examined collaborative recall for more complex emotional material. They asked Israeli students to collaborate in remembering the assassination of Prime Minister Rabin and found that groups showed the standard collaborative inhibition effect. Although Yaron-Antar and Nachson (2006) argued that collaborative inhibition occurs for personal, emotional material, the questions they used were largely semantic rather than autobiographical (e.g. "Who accompanied the prime minister to the hospital?"). Thus it remains unclear whether groups will invariably show costs of collaboration, even for more emotional and important everyday memories.

Overall, the findings from collaborative recall experiments are limited by the types of groups and the types of stimuli studied so far. Researchers have also tended to focus primarily on individual cognition and on the negative outcomes of group remembering (i.e., does the group remember less than the individual?). But in realworld group remembering, accuracy is only one goal of recall, and operates alongside social goals, such as establishing relationships or making a good impression, developing and maintaining intimacy, teaching and informing others, and eliciting or providing empathy (Alea \& Bluck, 2003). Thus, group memory may be qualitatively, not just quantitatively, different from individual memory. Laying aside these limitations, the collaborative recall paradigm offers a robust methodology for indexing the effects of discussion on memory, both during the discussion itself and on subsequent individual recall.

\subsection{Social contagion of memory}

The social contagion paradigm measures the impact on an individual's memory of recalling the same event with one or more other people. Procedurally, this paradigm is very similar to collaborative recall. In a typical social contagion experiment, participants first learn material, together with a confederate. Second, they recall with the confederate who introduces some incorrect details about the material. Third, participants recall again individually (see Fig. 3; e.g., Meade \& Roediger, 2002; Roediger, Meade, \& Bergman, 2001). In a variation of this paradigm, labelled the "memory conformity" procedure, participants in a group learn what appears to be the same material. However, unknown to them, each individual is shown a slightly different version of the same material (e.g., they see the same video of a robbery, but with slightly different details for the offender). Second, they recall together. Third, participants recall again individually (e.g., Gabbert, Memon, \& Allan, 2003). Whereas the collaborative recall paradigm focuses on the amount of correct information that is forgotten, the social contagion (and memory conformity) paradigm focuses on the amount of incorrect information that is remembered.

Roediger et al. (2001) found that people came to falsely remember items from a slideshow when they were suggested by a confederate during collaborative recall. In this experiment, final recall was private and individual, and accuracy was emphasised. In other experiments, participants were warned that the confederate may have mentioned false items (Meade \& Roediger, 2002). Thus, these participants did not simply add the suggested items to their recall to conform with the experimental demands or with the confederate, but rather because they genuinely believed the suggested items were present in the slideshow. Gabbert et al. (2003) extended this paradigm to a more natural setting, in which the participants engaged in discussions with other participants who, unknown to them, had seen a slightly different video of a crime. They found that $71 \%$ of witnesses who had discussed the event went on to recall individually items they had not themselves seen. Roediger et al. (2001) also reported benefits for social contagion similar to collaborative recall. Participants' subsequent individual recall was higher for the correct items introduced by the confederate, as well as the incorrect items. In other words, participants incorporated both correct and incorrect information into their recall following group collaboration.

Similar to the collaborative recall paradigm, the focus of comparisons within this paradigm is on the amount of information recalled; specifically, the number of contagion items recalled. Some research has indicated that the qualities of the suggested information can influence the social contagion effect, with false items that are more consistent with the genuine items more likely to be incorporated into recall (Roediger et al., 2001). However, other qualitative 


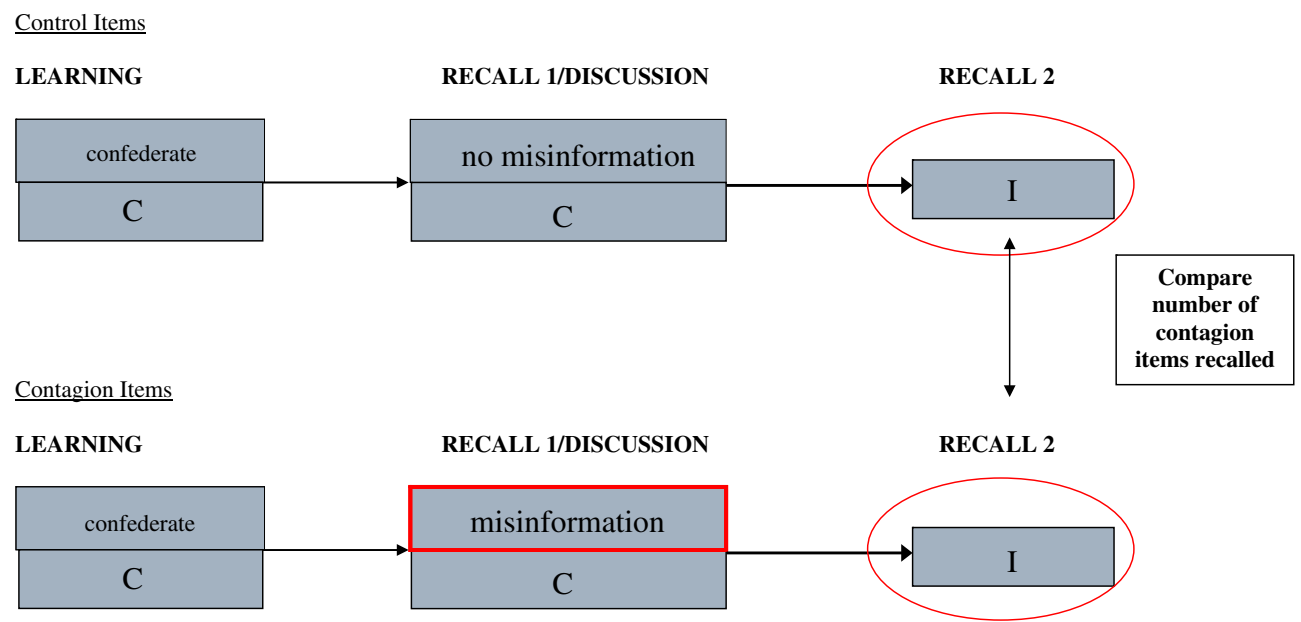

Fig. 3. Social contagion of memory procedure.

factors that are relevant to real world, autobiographical remembering, such as emotion and motivational value, have not been examined.

Social contagion effects often have been accounted for by a source monitoring explanation. According to the Source Monitoring Framework (Johnson, Hashtroudi, \& Lindsay, 1993) information from many sources can be utilised to construct a memory for an event. People are often not aware of where this information has come from, and may wrongly attribute information provided by someone else to the original event. In the context of the social contagion effect, the source monitoring framework suggests that people recall the information introduced by confederates because the source of this information is wrongly attributed to the original learning (Roediger et al., 2001).

Some experiments in this paradigm have examined the effects of different types of groups and group processes on the social contagion effect. For example, Meade and Roediger (2002) found that the social contagion effect was stronger when a real, present confederate introduced the incorrect items, compared to when participants read a written summary that included the misinformation. Also, the presence of dissenters in the group weakened the social contagion effect (Walther et al., 2002). Additionally, there is some evidence that memory contagion effects may be more likely to occur in discussion with a romantic partner than a stranger (French, Garry, \& Mori, 2006).

Whereas some experimenters have attempted to extend this social contagion paradigm to more ecologically valid stimuli, particularly in the forensic context (e.g., Gabbert et al., 2003), this research has not yet examined emotional, personally experienced autobiographical memories (but for examples of other false memory research see Garry \& Gerrie, 2005; Loftus, 2005, 1997; Sharman, Garry, \& Beuke, 2004).

\subsection{What needs to be measured}

Looking across these approaches and methods, there is much that we can fruitfully adopt and adapt. For example, the transactive memory literature suggests ways in which memories might be shared across individuals in some, but not necessarily in all types of groups. The collaborative recall and social contagion literatures highlight useful ways to index the varying influences of collaboration. As already noted, these literatures, as they currently stand, have their limitations. In terms of explanations, in the collaborative recall and social contagion literatures in particular there is a large gap between what researchers claim or hope to study - collective memory processesand the Triggering Thesis explanations they typically invoke, whereby remembering is seen as a cognitive process that takes place only and completely inside the heads of individuals (although it can be influenced by social phenomena). In terms of cases, although transactive memory theory, for instance, makes clear predictions about the kinds of groups that should show benefits of collaboration, there has been no real attempt within other cognitive paradigms to survey across a full range of memory cases and remembering groups. Most research in these traditions has involved individuals learning mundane, identical material and then recalling it collaboratively in convenience groups of mere acquaintances or strangers (undergraduate students); this does not really capture the full range of human remembering experiences. In terms of assumptions, while transactive memory assumes that collaboration can be positive, collaborative recall and social contagion are pessimistic about social influences on memory (but see Roediger et al., 2001). In these paradigms, memories are counted up and a lower number is invariably considered a poorer outcome for the group. Finally, in terms of what is measured, dependent variables in collaborative recall and social con- 
tagion paradigms are often limited to the amount recalled and its accuracy. This not only neglects the qualitative effects of collaboration, but completely misses the function of collaborating in groups about memories.

We believe that existing concepts and methods from cognitive psychology can be significantly extended and applied to a whole range of social memory phenomena when they are embedded within the theoretical framework of distributed cognition. In order to account adequately for the complete range of cases, we need studies that vary on at least the following six dimensions:

- Does the social distribution of memory concern the experiencing (encoding) or the remembering (retrieving) of an event?

- Is the experiencing of an event shared or unshared?

- Are the shared experiences generated accidentally or through more meaningful, intended joint activities?

- Are unshared experiences distinct or similar across the individuals who have them?

- Is the activity of remembering undertaken or manifested individually or as a member of a group?

$\square$ Is the activity of remembering as a member of a group minimally collaborative (e.g., turn-taking) or collaborative in some deeper sense (e.g., joint revisions)?

Considered together, these dimensions delineate a space of possibilities for further studies of social memory phenomena along the lines of the studies that we report below. And in developing a fruitful empirical framework within which to explore the role of social processes across this range of cases, we should design experiments that measure the following (independent and dependent) factors and variables, which we discuss in turn below:

- the costs and benefits of remembering in groups

- the parameters of group influence

- the fate of memories

- the function of group memory

Costs and benefits. In contemporary culture, external influences on personal memory often have been demonised as necessarily negative, leading inevitably to forgetting or distortion. But collaborating in remembering has clear benefits. Although research involving collaborative recall and social contagion has more typically focused on the costs of remembering in groups, these paradigms can measure the benefits as easily as the costs (e.g., Basden et al., 2000). Research needs to index whether people recall more, less, accurately, inaccurately, differently after collaborating. With collaborative recall and social contagion, we can index variables including: memories recalled vs. forgotten (since good forgetting is as important as good remembering), accurate vs. inaccurate recall (since groups are just as likely to misremember as individuals) and mem- ory quality (since memory quality, not just accessibility, may change).

Parameters of group influence. As noted in Section 2, and emphasised by our review of different research traditions, there is no agreed canonical definition of what counts as a group. Across the transactive memory, collaborative recall and social contagion literatures, group membership has varied from people who meet for the first time in their experiment to people in long-standing relationships. Similarly, group dynamics, in terms of the type of "sharing" that the group members engaged in, have varied from the minimal collaboration of enforced turntaking to the more genuine collaboration of a married couple remembering or problem solving as they would at home. Research should systematically investigate the effect of variations in the size, nature, aims, coherence and deliberative procedures of groups on the ways in which they and their members deal with the past. With collaborative recall and social contagion procedures, we can and should extend manipulations of the parameters of group influence, including the size and type of group, the manner of collaboration, the similarity (or sharing) of memories and retrieval strategies, and social and motivational factors.

The fate of memories. Some discussions of "collective memory" have focused on the ways in which individuals' disparate memories of an event may become more similar over time - more shared-by talking together about the past. The possibility of such "mnemonic convergence" (Hirst, Manier, \& Cuc, 2003) demands that research map how individuals' memories change over time, especially after group collaboration. Although collaborative recall and social contagion have focused mostly on the costs of collaborating, these paradigms can map the fate of memories across repeated tests and as groups form, part, and reform: what did the participant remember vs. forget individually at time 1 , collaboratively at time 2 , then individually at time 3 ? Even studies of simple word lists indicate that as individuals lose memories, groups gain them (Basden et al., 2000). With collaborative recall and social contagion we can index the epidemiology of remembering; why, in Hirst et al. (2003) terms some memories spread quickly, but other die off.

The function of group memory. As noted in Section 2, autobiographical memory plays an important role in the daily life of individuals and groups: in defining identity, in teaching and communicating, in developing and maintaining relationships, in representing (individual or group) self to self and to others. By extending cognitive memory paradigms outside the relatively contrived social context of the laboratory and among real groups - to families, school friends, couples, business associates, etc.-we can consider the function of group memory. What do the memories mean to the individuals and to their groups? How do memories contribute to a sense of (individual and group) identity? Is remembering in groups motivated in the same way as individual memory? 


\section{Early empirical evidence}

In Sections 2 and 3 above we laid out a conceptual and empirical framework for investigating social influences on memory. In this Section we describe early empirical work in which we are putting this framework into action. The aim of our early work has been to adapt and use collaborative recall and social contagion paradigms in ways that build on their extensive existing database, that significantly extend the range of memory cases studied to date, that focus on personal and significant autobiographical memories across a range of "shared" and "unshared" cases, and that develop the features of our empirical framework.

\subsection{Social contagion of autobiographical memories}

Our first study adapted the social contagion paradigm to recent, significant autobiographical events experienced and remembered by 48 ( 28 female, 18 male) university students from the University of New South Wales. In our version of the paradigm (based closely on Roediger et al., 2001), participants were (individually) prompted to recall and describe memories of important recent events: their 19th birthday, their first HSC exam, ${ }^{1}$ their school graduation dance, and their first day of university. In a session 1 week later, they took turns with a confederate to describe their autobiographical memories of the different events. For instance, the participant described his or her (genuine) memory of their 18th birthday, and then the confederate described his or her (apparent) memory of their 18th birthday; the confederate's "memories" were standardised scripted versions that we wrote. In the next phase of the study, the participant and the confederate took turns to describe back to their recall partner the five or six most important parts of the other person's memory of each event. So, the participant described the five or six most important points of the confederate's (apparent) 18th birthday memory, then the confederate described the five or six most important points of the participant's (genuine) 18th birthday memory. Notably, as one of the five or six points, the confederate included a contagion item (for two of the four events): a piece of either positive or negative information that the participant had not generated about their event (e.g., for the 18th birthday memory, the confederate might say that the participant recalled "you thought that this was a big turning point in your life"). In the final phase, the participant and confederate separated for a final individual recall; the confederate did not recall (Fig. 4).

In terms of our distinctions and dimensions, participants' experiences were unshared, but similar. Although each participant did not experience the events (e.g., their 18 th birthday) with their collaborating partner (the confed-

\footnotetext{
${ }^{1}$ HSC refers to "Higher School Certificate". It is the group of major exams sat by all final year high school students in New South Wales, Australia.
}

erate), the confederate described similar events. But their remembering was in a group; their collaboration was moderately interactive - it was more than turn taking but less than truly co-constructing a joint past. This study also allowed us to index the costs and benefits of remembering in a group (what and how they remembered vs. what and how they forgot).

We found a strong social contagion effect for autobiographical memories. Overall, approximately $30 \%$ of participants included in their final recall at least one social contagion idea unit for at least one event where the confederate introduced a contagion item (cf., Meade \& Roediger, 2002; Roediger et al., 2001). For example, participants who received the contagion item for their 18th birthday memory, "you thought that this was a big turning point in your life", often included either this exact piece of information or the gist of it in their final recall. Sometimes the effect was more subtle: at initial recall one participant said there were 30 people at her birthday party, after the contagion item of "a big turning point", she said there were 70 people at her birthday party. There was no difference in the "take up" of positive and negative contagion items, although contagion was more successful for some events than others (e.g., 18th birthday party vs. first day at university).

We also found a very high level of unsuggested contagion, whereby the participant incorporated into their final recall new information that appeared to come from the confederate's "memories". Of course, the confederate's memories might simply have prompted recall by the participant of a previously unmentioned genuine element of their experience of the event, as the Triggering Thesis would suggest. But alternatively, our findings may indicate a form of Social Manifestation, in that brief collaboration with a virtual stranger, the confederate, was sufficient to slightly alter the later remembering of participants' private experiences. Of particular note, some participants adopted and elaborated on information presented by the confederate into their own autobiographical memories. This highlights the robust nature of the social contagion paradigm and its value in exploring the consequences of collaborative shaping of shared and even unshared autobiographical events.

\subsection{Collaborative flashbulb memories of the death of Steve Irwin}

Our second study adapted the collaborative recall paradigm to focus on another way that events become socially shared-when they are culturally important and receive extensive media coverage. Memories of events like these can become "flashbulb memories" (Brown \& Kulik, 1977; Conway, 1995), where individuals maintain longstanding vivid (but not necessarily accurate) memories of hearing about the event (e.g., for flashbulb memory studies of the Challenger space shuttle disaster, of the death of Diana, Princess of Wales, and of 9/11; see Curci \& Luminet, 2006; Kvavilashvili, Mirani, Schlagman, \& Kornbrot, 


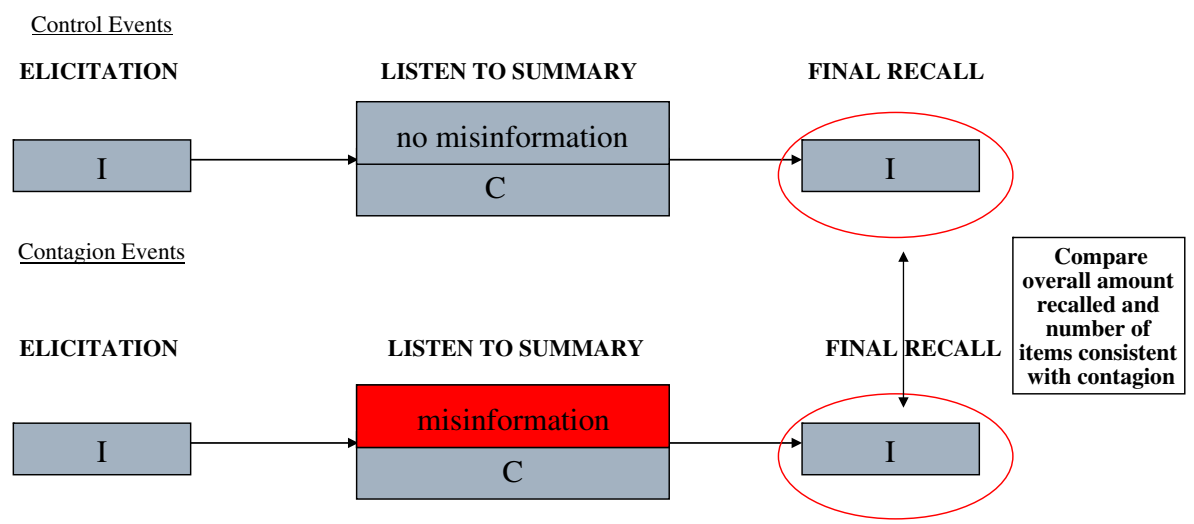

Fig. 4. Social contagion of autobiographical memory procedure.

2003; Neisser \& Harsch, 1992). Such events are experienced both individually and socially, and are remembered both individually and socially. Another feature of culturally significant events is that one's social group can dictate a set of norms about how we should react or think about such an event (Skowronski \& Walker, 2004).

On the afternoon of the 4th of September 2006 news broke that Steve Irwin, Australian entertainer and "wildlife warrior", had been killed by a stingray while filming a documentary in far North Queensland. Both in Australia and worldwide, the news of Steve Irwin's death was met with large-scale public grief. His death and its aftermath dominated the media for weeks afterwards, was the subject of tributes and memorials, and any criticism of Irwin was treated harshly by the media (Coultan, Coorey, \& Tadros, 2006; Wainwright \& Baker, 2006; Williams \& Hearn, 2006). In this context of public mourning and commemoration, we asked 69 university students from the University of New South Wales to come to our laboratory and discuss their memories of hearing about Steve Irwin's death and their reactions to the news. These interviews took place over a period of 5 weeks, between 2 and 7 weeks following Irwin's death (Fig. 5).
First we asked all participants to complete a survey about their memory for the events of Steve Irwin's death. We asked them to provide: personal autobiographical details (e.g., where they were, how they found out), semantic knowledge about the event (e.g., how Irwin died, how the media responded), and ratings of their beliefs and feelings about the impact and significance of Irwin's death, both for themselves and for Australians in general. Following this survey, half of the participants took part in collaborative recall of Irwin's death. In groups of three, we asked them to discuss together for $10 \mathrm{~min}$ their experiences of the events surrounding Irwin's death and their reactions to his death. The other half of the participants took part in individual recall. Individually, we asked them to think for $10 \mathrm{~min}$ about their experiences of the event and their reactions and to write down on a piece of paper whatever came to mind. We emailed all participants 1 week after this session and again one month after this session and asked them to complete a second and then a third version of the original survey. In other words, participants provided autobiographical details, semantic knowledge, and ratings about Steve Irwin's death on three occasions: (1) at the beginning of the experiment and before collaborative or individual

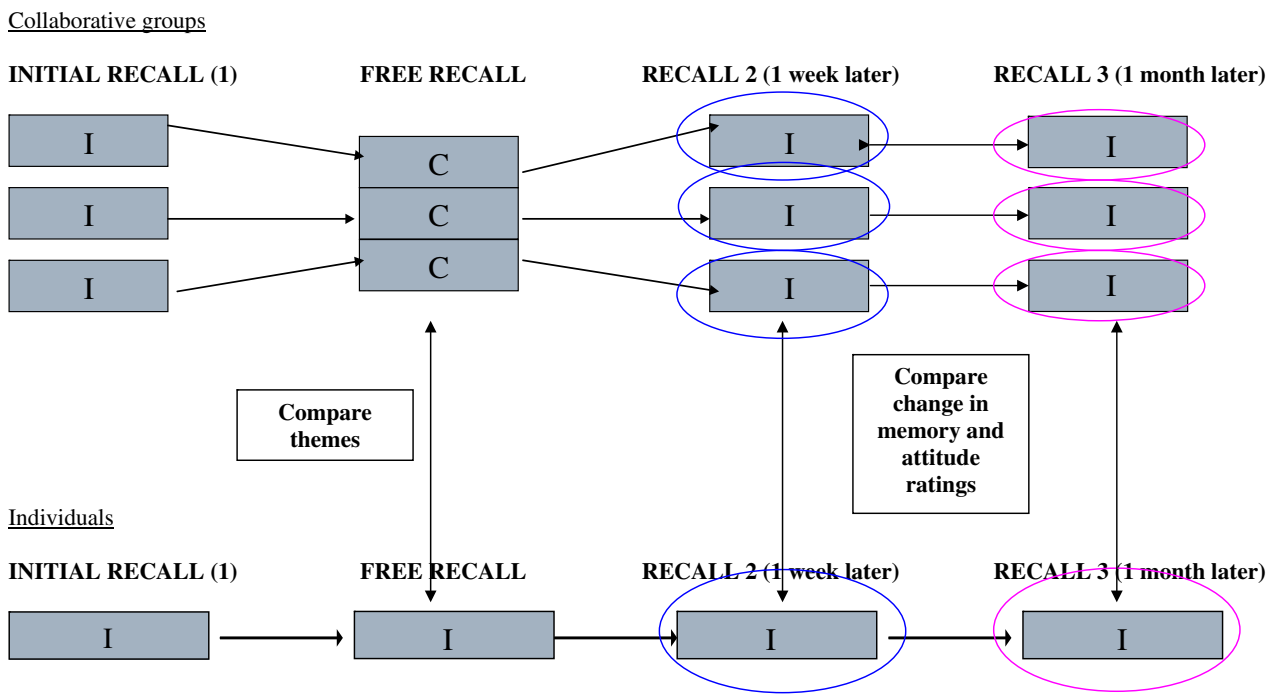

Fig. 5. Collaborative recall of Steve Irwin's death procedure. 
recall, (2) 1 week after the session and after collaborative or individual recall, and (3) one month after the session and after collaborative or individual recall.

In terms of our distinctions and dimensions, participants experienced the events surrounding Steve Irwin's death individually (or at least not with their collaborating partners), but their experiences were similar and knowledge about and reactions to this event were extensively shared in the public domain. Our participants' remembering, at least within the context of our experiment, was either in a group or individual. But of course, most participants had talked about - had shared - their reactions to Irwin's death before they arrived in our laboratory. Those who collaborated in the study did so very interactively, as we'll see below. This study also allowed us to index the costs and benefits of remembering in a group (what and how they remembered vs. what and how they forgot) and the fate of memories (how their memories changed over time, especially after group interaction).

In the free recall session, we noticed that the themes that emerged during the discussion were quite different from those that emerged when participants thought and wrote about the event alone. Participants who thought and wrote about the event alone were more likely to say they were personally upset by Irwin's death, while participants who discussed the event were likely to minimize their own personal emotional reaction to the event. However, both groups of participants were likely to mention that they were sad for Irwin's family. Both groups of participants mentioned experiencing shock and disbelief when hearing of Irwin's death, but during discussion participants frequently mentioned that the event was not surprising, given the dangerous nature of Irwin's job. Whereas people who thought and wrote about the event alone often emphasised the significance of the event and Irwin's 'hero' status, participants who discussed the event often said that the media exaggerated Irwin's importance; these participants minimized the significance of the event.

The following excerpt from a discussion demonstrates the process of negotiation that occurred during the group discussion, where the appropriate reaction to the event and its meaning were established:

$\mathrm{K}$ : I know people who cried when they were watching the memorial service when Bindi was doing her speech

E: Yeah, that was really sad! I don’t know anybody who actually cried...

M: Did you cry?

K: Can't say that I did.

M: Do you know anyone who cares at all?

E: I don't think people...

$\mathrm{K}$ : I think people feel bad for him, a lot of people...

M: People die every day...

One notable feature of this exchange is the lack of personal identification with the emotions mentioned; emotions are attributed to "people" in general, rather than to individual participants. This contrasts with the comments made by individuals, who wrote things like: "[Irwin] will be remembered throughout Australia and worldwide history forever"; "it feels as though you know him, and maybe that is why his death is so sad"; "It is unbelievable how much he affected everybody's lives"; "to this day, I still feel shock and sadness, simply because why him? He is such a good person".

Collaborative recall not only influenced the content of recollections during the free recall session, but it influenced the way participants later remembered their reaction to hearing the news of Steve Irwin's death. One week after the initial recall and free recall session, participants who discussed the event had significantly reduced their ratings of how shocked and how upset they had been when they heard the news, while those who thought and wrote about the event alone had not significantly changed their ratings. One month later, all participants rated themselves as being less upset upon hearing of Irwin's death than they had initially. However, participants who discussed the event had even further reduced their ratings of how shocked they had been when they heard the news, while the rated shock of participants who thought and wrote about the event alone remained the same as at initial recall. Similarly, one month later, participants who discussed the event rated Steve Irwin's death as less significant for Australia than they had initially, while the ratings of people who thought and wrote about the event alone remained unchanged. Collaborating with others also influenced confidence. One month after their discussion, participants who collaborated remained as confident about the semantic details of the event as they had been in the initial session. Although participants who thought and wrote about the event alone were no less accurate than their collaborating counterparts, they felt less confident about the semantic details of the events surrounding Steve Irwin's death one month after the session. There was no evidence that participants revised their ratings simply to meet perceived experimental demands. They had no access to their initial ratings, they didn't seem aware that their 1 week and 1 month ratings changed, and the ratings of those who collaborated and those who did not were different; this all argues against an explanation on the basis that participants explicitly referred back to their earlier ratings (rather than to their memories).

These early results suggest that collaborative recall can be quite easily and usefully extended to more complex and personally relevant memories. We revealed clear differences between those who collaborated in memory and those who remembered alone, especially in terms of the fate of their memories. Interestingly, these differences were not in terms of how much or how little was recalled (we did not focus on accuracy) over repeated tests, but rather in terms of the qualitative features of individuals' rememberingespecially during collaboration - and the emotional reactions recalled later about the target event. In this study, collaborative recall yielded robust differences between people who we simply brought together to discuss a culturally 
shared event. We predict even stronger results when we turn to focus on established, real-world groups, as in our next study, Study 3.

\subsection{Memories of high school at a high school reunion}

In our third study, still underway, we approached former students of a Sydney high school at their 20 year high school reunion and asked them to complete a survey about their memories of high school. We asked participants: to list their school friends and to tell us whether they had kept in touch, to indicate how often they had thought about or discussed events that happened in high school (either with high school friends or with other friends and family), to describe their memory experiences at the reunion, to recall the most memorable events from high school, and to recall as much as possible about four significant events (a football match, a school musical, their first HSC exam, their graduation dance). In terms of our distinctions and dimensions, these former high school students experienced the same events, often together. For many, their experiencing was not accidental, but rather intentional and truly shared. However, their remembering was either in a group or individual. We were particularly interested in the memories of former students who maintained contact with their classmates over time and those who did not. Thus, this study allowed us to index the parameters of group influence. This study also allowed us to index the fate of memories (how their memories changed over time, especially depending on group interaction) and the function of group memory (what the memories meant to the individuals and to their groups) (Fig. 6).

One male former student reported only occasional contact over the past 20 years. When describing the reunion he said: "I thought it interesting that in most conversations I heard or overheard were mainly discussing current lives and experiences since school. There was little fond reminiscing of school times or discussions of school events." When asked about an important football match that took place in 1985, this former student wrote: "I went and I recall we lost. That's it."

In contrast to this student's limited contact with his former classmates and lack of details in remembering, another former female student reported regular contact over the past 20 years. In fact, she married one of her classmates. She wrote: "It is an advantage having my school friends as my dearest friends \& husband as we often recall our school days but usually just revisiting the same classic stories". Her survey responses described many events in great detail. When asked about the football match, she wrote: "Thank God they made the final as they (Rugby bods) were a bit precious at school. Our Captain and the rest of the footyheads up against the slick outfit from St. Eddy's including a young Ricky Stuart who was playing in the final again after repeating yr 12 but shows up driving a lovely new Honda. [Our Captain] played v. well but was always overshadowed by Ricky, even when Australian Schoolboys team was selected. ... Don't remember much of the game spent more time socialising as I ( \& everybody else) never expected us to win. It was a school spirit/support event with a friend in the team, classmates too ... otherwise I wasn't that interested."

Another former student, a male, who maintained regular contact with classmates over the past 20 years and who had friends in the football team similarly described the football match in great detail. When asked whether being at the reunion triggered specific memories of high school, he wrote: "Looking at the new sports hall and the trophy cabinet standing with my mate bought back a memory of how the First 15 [the rugby team] made it to

Not kept in touch

EXPERIENCE (LEARNING) TEMEMBERING OVER TIME RESPONSES TO SURVEY
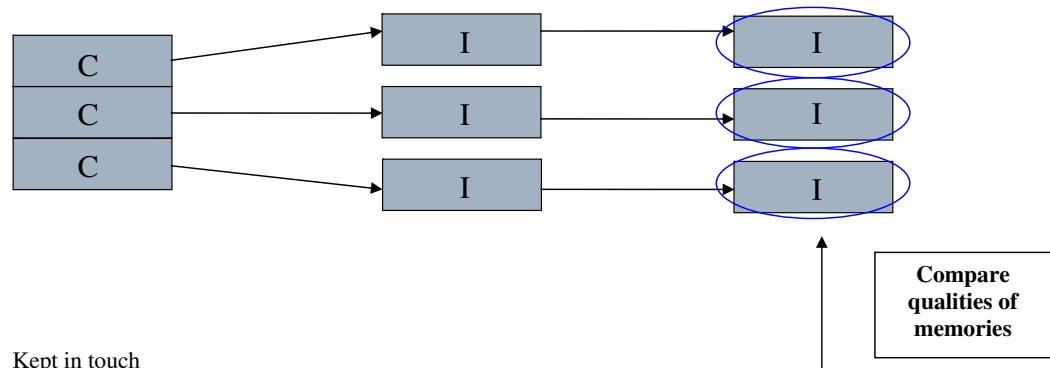

Kept in touch

EXPERIENCE (LEARNING) REMEMBERING OVER TIME RESPONSES TO SURVEY

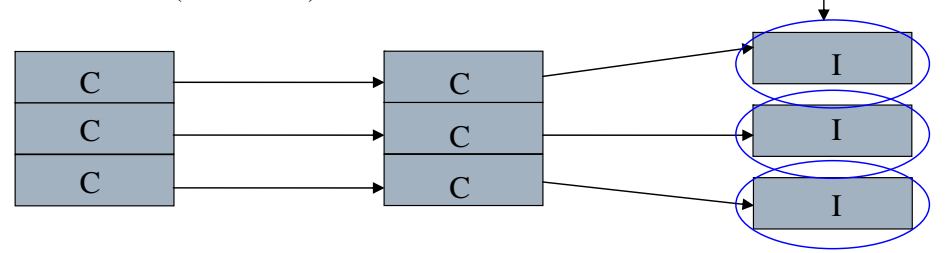

Fig. 6. School reunion study procedure. 
the Waratah Shield Final in 1985. My two mates who I kept in contact with after school played in that match, and I was there to support. The trophy cabinet jogged that memory." When asked specifically about the football match, he wrote: "[The School's] First 15 made it to the Waratah Shield Final in 1985. Two mates were in the team. It was played at the SCG as the curtain raiser to the Australian V Fiji Rugby Test. We played St Edmonds from Canberra. We were beaten by them and in particular one player. Their half back was Ricky Stuart who went on to be a great halfback in rugby league and is currently the Australian Rugby League Coach. We had a bus supplied to take the supporters to the SCG. We had to go down in our uniforms. We sat on the old hill to watch the game."

One interpretation of these individual differences in recollection, consistent with the Triggering Thesis, is that these former students simply had different experiences at the time and different memory styles now. However, the sharing of experiencing and the sharing of remembering seemed to flavour the quantity and quality of their recollections of high school events, findings more consistent with the Social Manifestation Thesis. For instance, when asked about their first HSC exam, the first male student who mostly fell out of contact with school friends wrote: "I think it was English. Arrived at the hall for the exam, took the test and drove home to prepare for my other exams. Nothing special really." In contrast, the second male student who (interestingly) had friends in common with the first male student, but who kept in contact and indicated that he and his friends regularly discussed school events during the past 20 years, described this first exam in colourful detail. He wrote: "I got to my exam early-English. At the time we had ID cards that had to be on you so to sit the exam. My best mate forgot his ID card. I had a car-red Holden HR - so I drove my mate to his home in [name of suburb] to pick up his ID card. We drove like a bat out of hell as time was running out. We got back to the school and everyone had entered the hall. We were the last two in. Everyone was seated - the exam had not started. My mate sat relatively close to the door (surname starting with $\mathrm{M}$ ) but for me surname starting with A I had to walk right across the whole hall to my seat. Most embarrassing. Got through the exam OK, had a big laugh about being late after the exam." $\mathrm{He}$ and his mate remained close friends for 20 years and one can imagine them revisiting this event again and again and laughing.

In the next phase of this study we plan to invite the following groups of former classmates back to the laboratory for a collaborative recall study in which we explore their individual and group remembering: (a) groups of former students who were friends and who kept in touch, (b) groups of former students who were friends but who fell out of touch, and (c) groups of former students who were not friends at school. In this way, we can start to map the impact of the group on the fate and function of shared and unshared autobiographical memories, and whether new capacities emerge when people remember with others.

\section{Concluding remarks}

Sue Campbell has recently argued (in press) that many philosophers are attracted to what we have called the Triggering Thesis - the idea that social and other external factors are merely cues or triggers to the individual's internal memory processes - both because it seems to shore up epistemological confidence in our autonomous access to truths about the past, and because it draws clean lines around the boundaries of the person. They are nervous, Campbell suggests, that if the sharing of memories "amounts to more than cuing, then somehow the integrity of the self as a record of its own history has given way and is giving way all the time and in ways that we cannot even track" (p. 4). We agree with Campbell, in contrast, that such alarmism should be resisted, because it is ordinary and appropriate for both self and memory to be socially manifested (Campbell, in press, p. 3):

Sharing memory is how we learn to remember, how we come to reconceive our pasts in memory, how we come to form a sense of self, and one of the primary ways in which we come to know others and form relationships with them, reforming our sense of self as we come repeatedly under the influence not only of our own pasts as understood by others but of the pasts of others.

To this salutary reminder of the range of social memory phenomena, in this paper we have added, firstly, a distinct theoretical basis for understanding the social distribution of cognition, which can place different cases in a multidimensional space, and, secondly, a number of extensions and new applications of existing paradigms in the cognitive psychology of memory. Our initial empirical studies, reported in Section 4, are first steps towards broader investigations into the costs and benefits of remembering in groups, the parameters of group influence, the fate of memories over time, and the function of group memory. As we seek to apply the distributed cognition framework to more complex real-world examples of the social distribution of remembering, further conceptual and methodological innovations will be required, and the resources of cognitive psychology and the philosophy of mind will need to be still more thoroughly integrated.

\section{Acknowledgements}

The preparation of this paper and the research we report is part of a larger long-term project by the first two authors on individual and group memory, and was supported by: (1) an Australian Research Council Australian Research Fellowship to Amanda Barnier, (2) an Australian Research Council Discovery-Project Grant (DP0770271) to Amanda Barnier and John Sutton, as well as by (3) an individual 3 year grant from the Social Sciences and Humanties Research Council of Canada to Rob Wilson. We are grateful for that support. We are grateful also to Rochelle Cox for 
assistance with the manuscript, and to three anonymous reviewers for Cognitive Systems Research for their useful suggestions.

\section{References}

Adams, F., \& Aizawa, K. (2001). The bounds of cognition. Philosophical Psychology, 14, 43-64.

Adams, F., \& Aizawa, K. (2007). The bounds of cognition. Oxford: Blackwell.

Alea, N., \& Bluck, S. (2003). Why are you telling me that? A conceptual model of the social function of autobiographical memory. Memory, 11, $165-178$.

Anderson, J., \& Ronnberg, J. (1995). Recall suffers from collaboration: Joint recall effects of friendship and task complexity. Applied Cognitive Psychology, 9, 273-287.

Austin, J. R. (2003). Transactive memory in organisational groups: The effects of content, consensus, specialization, and accuracy on group performance. Journal of Applied Psychology, 88, 866-878.

Barnier, A. J., Conway, M. A., Mayoh, L., Speyer, J., Avizmil, O., \& Harris, C. B. (2007). Directed forgetting of recently recalled autobiographical memories. Journal of Experimental Psychology: General, 136, 301-322.

Barnier, A. J., Hung, L., \& Conway, M. A. (2004). Retrieval-induced forgetting of autobiographical episodes. Cognition \& Emotion, 18, 457-477.

Basden, B. H., Basden, D. R., Bryber, S., \& Thomas, R. L. III, (1997). A comparison of group and individual remembering: Does collaboration disrupt retrieval strategies? Journal of Experimental Psychology: eLearning, Memory and Cognition, 23, 1176-1189.

Basden, B. H., Basden, D. R., \& Henry, S. (2000). Costs and benefits of collaborative remembering. Applied Cognitive Psychology, 14, 497-507.

Beach, K. (1988). The role of external mnemonic symbols in acquiring an occupation. In M. M. Gruneberg \& R. N. Sykes (Eds.). Practical aspects of memory (Vol. 1, pp. 342-346). New York: Wiley.

Bloch, M. (1998). How we think they think: Anthropological approaches to cognition memory and literacy. Boulder, CO: Westview Press.

Brown, R., \& Kulik, J. (1977). Flashbulb memories. Cognition, 5, 73-99.

Campbell, S. (2003). Relational remembering: Rethinking the memory wars. Lanham, Maryland: Rowman \& Littlefield.

Campbell, S. (2006). Our faithfulness to the past: Reconstructing memory value. Philosophical Psychology, 19, 361-380.

Campbell, S. (in press). The second voice. Memory Studies, 1.

Clark, A. (1997). Being there: Putting brain body and world together again. Cambridge, MA: MIT Press.

Clark, A. (2001). Mindware. Oxford: Oxford University Press.

Clark, A. (2003). Natural-born cyborgs: Minds technologies and the future of human intelligence. Oxford: Oxford University Press.

Clark, A. (2007). Re-inventing ourselves: The plasticity of embodiment, sensing, and mind. Journal of Medicine and Philosophy, 32, 263-282.

Clark. A. (in press). Memento's revenge: The extended mind extended. In R. Menary (Ed.), The extended mind. Aldershot: Ashgate.

Clark, A., \& Chalmers, D. (1998). The extended mind. Analysis, 58, 7-19.

Conway, M. A. (1995). Flashbulb memories. Hillsdale, NJ: Lawrence Erlbaum.

Conway, M. A. (2005). Memory and the self. Journal of Memory \& Language, 53, 594-628.

Coultan, M., Coorey, P., \& Tadros, E. (2006). Worldwide praise for a bloody good bloke. The Sydney Morning Herald. Available from http://www.smh.com.au/news/national/ worldwide-praise-for-a-bloodygood-bloke/2006/09/04/1157222072720.html.

Cuc, A., Ozuru, Y., Manier, D., \& Hirst, W. (2006). On the formation of collective memories: The role of a dominant narrator. Memory \& Cognition, 34, 752-762.

Curci, A., \& Luminet, O. (2006). Follow-up of a cross-national comparison on flashbulb and event memory for the September 11th attacks. Memory, 14, 329-344.
Finlay, F., Hitch, G. J., \& Meudell, P. (2000). Mutual inhibition in collaborative recall: Evidence for a retrieval-based account. Journal of Experimental Psychology: Learning, Memory and Cognition, 26, $1556-1567$

Fiske, S. T., \& Goodwin, S. A. (1994). Social cognition research and small group research: A west-side story or ...? Small Group Research, 25, $147-171$.

French, L., Garry, M., \& Mori, K. (2006). Discussion affects memory more in romantic partners than in strangers. Paper presented at the 4th international conference on memory, Sydney, July 2006.

Gabbert, F., Memon, A., \& Allan, K. (2003). Memory conformity: Can eyewitnesses influence each other's memories for an event? Applied Cognitive Psychology, 17, 533-543.

Garry, M., \& Gerrie, M. P. (2005). When photographs create false memories. Current Directions in Psychological Science, 14, 321-324.

Giere, R. (2002). Scientific cognition as distributed cognition. In P. Carruthers, S. Stich, \& M. Siegal (Eds.), Cognitive bases of science (pp. 285-299). Cambridge: Cambridge University Press.

Gilbert, M. (1989). On social facts. London: Routledge.

Gilbert, M. (2003). The structure of the social atom: Joint commitment as the foundation of human social behaviour. In F. F. Schmitt (Ed.), Socializing metaphysics (pp. 39-64). Lanham, MD: Rowman and Littlefield.

Gould, O. N., Osborn, C., Krein, H., \& Mortenson, M. (2002). Collaborative recall in married and unacquainted dyads. International Journal of Behavioral Development, 26, 36-44.

Griffiths, P. E., \& Stotz, K. (2000). How the mind grows: A developmental perspective on the biology of cognition. Synthese, 122, 29-51.

Halverson, C. A. (2002). Activity theory and distributed cognition: Or, what does CSCW need to do with theories? Computer Supported Cooperative Work, 11, 243-267.

Harris, C. B., Paterson, H. M., \& Kemp, R. I. (in press). Collaborative recall and collective memory: What happens when we remember together? Memory.

Haugeland, J. (1998). Mind embodied and embedded in his having thought: Essays, in the metaphysics of mind. Cambridge, MA: Harvard U.P, pp. 207-237.

Hirst, W., \& Manier, D. (in press). Towards a psychology of collective memory. Memory.

Hirst, W., Manier, D., \& Cuc, A. (2003). The construction of a collective memory. In B. Kokinov \& W. Hirst (Eds.), Constructive memory (pp. 111-116). Sofia: New Bulgarian University.

Hoerl, C., \& McCormack, T. (2005). Joint reminiscing as joint attention to the past. In N. Eilan, C. Hoerl, T. McCormack, \& J. Roessler (Eds.), Joint attention: Communication and other minds (pp. 260-286). Oxford: Oxford University Press.

Hollan, J., Hutchins, E., \& Kirsh, D. (2000). Distributed cognition: Toward a new foundation for Human-Computer Interaction Research. ACM Transactions on Computer-Human Interaction, 7, 174-196.

Hollingshead, A. B. (1998a). Retrieval processes in transactive memory systems. Journal of Personality and Social Psychology, 74, 659-671.

Hollingshead, A. B. (1998b). Communication, learning, and retrieval in transactive memory systems. Journal of Experimental Social Psychology, 34, 423-442.

Hutchins, E. (1995). Cognition in the wild. Cambridge, MA: MIT Press.

Hutchins, E. (2006). Imagining the cognitive life of things. Presented at workshop on 'The cognitive life of things: Recasting the boundaries of the mind', McDonald Institute for Archaeological Research, Cambridge, April. Available from http://liris.cnrs.fr/enaction/enaction06/documents/ImaginingCogLifeThings.pdf.

Johnson, M. K., Hashtroudi, S., \& Lindsay, D. S. (1993). Source monitoring. Psychological Bulletin, 114, 3-28.

Kansteiner, W. (2002). Finding meaning in memory: A methodological critique of collective memory studies. History and Theory, 41, 179-197.

Kirsh, D. (1996). Adapting the environment instead of oneself. Adaptive Behavior, 4, 415-452. 
Kirsh, D. (2000). A few thoughts on cognitive overload. Intellectica, 30, $19-51$.

Kirsh, D. (2006). Distributed cognition: A methodological note. Pragmatics and Cognition, 14, 249-262.

Klein, K. L. (2000). On the emergence of memory in historical discourse. Representations, 69, 127-150.

Knappett, C. (2005). Thinking through material culture: An interdisciplinary approach. Philadelphia: University of Pennsylvania Press.

Koning, J.-L., \& Ling, C. X. (2003). Cognitive agents and multiagent interaction. Cognitive Systems Research, 4, 167-168.

Kvavilashvili, L., Mirani, J., Schlagman, S., \& Kornbrot, D. E. (2003). Comparing flashbulb memories of September 11 and the death of Princess Diana: Effects of time delays and nationality. Applied Cognitive Psychology, 17, 1017-1031.

List, C. (in press). Distributed cognition: A perspective from social choice theory. In M. Albert, D. Schmidtchen, \& S. Voigt (Eds.), Scientific competition: Theory and policy. Tuebingen: Mohr Siebeck.

Loftus, E. F. (1997). Creating false memories. Scientific American, 277, $50-55$.

Loftus, E. F. (2005). Planting misinformation in the human mind: A 30year investigation of the malleability of memory. Learning \& Memory, $12,361-366$.

Lutz, D. R., \& Keil, F. C. (2002). Early understanding of the division of cognitive labor. Child Development, 73, 1073-1084.

McClelland, J. L. (1995). Constructive memory and memory distortions: A parallel distributed processing approach. In D. L. Schacter (Ed.), Memory Distortion: How minds, brains, and societies reconstruct the past (pp. 69-90). Cambridge, MA: Harvard University Press.

Meade, M. L., \& Roediger, H. L. (2002). Explorations in the social contagion of memory. Memory \& Cognition, 30, 995-1009.

Menary, R. (2006). Attacking the bounds of cognition. Philosophical Psychology, 19, 329-344.

Neisser, U., \& Harsch, N. (1992). Phantom flashbulbs: False recollections of hearing the news about Challenger. In E. Winograd \& U. Neisser (Eds.), Affect and accuracy in recall: Studies of flashbulb" memories (pp. 9-31). New York, NY, US: Cambridge University Press.

Nelson, K. (2003). Self and social functions: Individual autobiographical memory and collective narrative. Memory, 11, 125-136.

Nelson, K., \& Fivush, R. (2004). The emergence of autobiographical memory: A social cultural developmental theory. Psychological Review, 111, 486-511.

Norman, D. (1993). Things that make us smart. Reading, MA: AddisonWesley.

Ohtsubo, Y. (2005). Should information be redundantly distributed among group members? Effective use of group memory in collaborative problem solving. Applied Cognitive Psychology, 19, 1219-1233.

Okasha, S. (2007). Evolution and the levels of selection. New York: Oxford University Press.

Olick, J. K. (1999). Collective memory: The two cultures. Sociological Theory, 17, 333-348.

Pettit, P. (2003). Groups with minds of their own. In F. F. Schmitt (Ed.), Socializing metaphysics (pp. 167-193). Lanham, MD: Rowman and Littlefield.

Pettit, P., \& Schweikard, D. (2006). Joint actions and group agents. Philosophy of the Social Sciences, 36, 18-39.

Poirier, P., \& Chicoisne, G. (2006). A framework for thinking about distributed cognition. Pragmatics and Cognition, 14, 215-234.

Reese, E. (2002). A model of the origins of autobiographical memory. In J. W. Fagen \& H. Hayne (Eds.). Progress in infancy research (Vol. 2, pp. 215-260). Hillsdale, NJ: Erlbaum.

Ren, Y., Carley, K. M., \& Argote, L. (2006). The contingent effects of transactive memory: When is it more beneficial to know what others know? Management Science, 52, 671-682.

Roediger, H. L., Meade, M. L., \& Bergman, E. T. (2001). Social contagion of memory. Psychonomic Bulletin \& Review, 8, 365-371.

Rowlands, M. (1999). The body in mind: Understanding cognitive processes. Cambridge, UK: Cambridge University Press.
Rozenblit, L., \& Keil, F. (2002). The misunderstood limits of folk science: An illusion of explanatory depth. Cognitive Science, 92, 1-42.

Rupert, R. (2004). Challenges to the hypothesis of extended cognition. Journal of Philosophy, 101, 389-428.

Schacter, D. L. (1999). The seven sins of memory. American Psychologist, $54,182-203$.

Schwartz, B., \& Schuman, H. (2005). History, commemoration and belief: Abraham Lincoln in American memory, 1945-2001. American Sociological Review, 70, 183-203.

Searle, J. (2006). Social ontology: Some basic principles. Anthropological Theory, 6, 12-29.

Sharman, S. J., Garry, M., \& Beuke, C. J. (2004). Imagination or exposure causes imagination inflation. American Journal of Psychology, 117, $157-168$.

Skowronski, J. J., \& Walker, W. R. (2004). How describing autobiographical events can affect autobiographical memories. Social Cognition, 22, 555-590.

Smith, L. B., \& Thelen, E. (2003). Development as a dynamic system. Trends in Cognitive Sciences, 7, 343-348.

Sober, E., \& Wilson, D. S. (1998). Unto others: The evolution and psychology of unselfish behavior. Cambridge, MA: Harvard University Press.

Sterelny, K. (1996). The return of the group. Philosophy of Science, 63, $562-584$.

Sutton, J. (2002a). Porous memory and the cognitive life of things. In D. Tofts, A. Jonson, \& A. Cavallaro (Eds.), Prefiguring cyberculture: An intellectual history (pp. 130-141). Cambridge, MA \& Sydney: MIT Press.

Sutton, J. (2002b). Cognitive conceptions of language and the development of autobiographical memory. Language and Communication, 22, $375-390$.

Sutton, J. (2004). Representation, reduction, and interdisciplinarity in the sciences of memory. In H. Clapin, P. Staines, \& P. Slezak (Eds.), Representation in mind: New approaches to mental representation (pp. 187-216). Amsterdam: Elsevier.

Sutton, J. (in press-a). Exograms and interdisciplinarity: History, the extended mind, and the civilizing process. In R. Menary (Ed.), The extended mind. Aldershot: Ashgate.

Sutton, J. (in press-b). Remembering. In M. Aydede, \& P. Robbins (Eds.), The Cambridge handbook of situated cognition. Cambridge: Cambridge University Press.

Tindale, R. S., \& Sheffey, S. (2002). Shared information, cognitive load, and group memory. Group processes and intergroup relations, 5, 5-18.

Tollefsen, D. P. (2006). From extended mind to collective mind. Cognitive Systems Research, 7, 140-150.

Tribble, E. (2005). Distributing cognition in the Globe. Shakespeare Quarterly, 56, 135-155.

van Leeuwen, C., Verstijnen, I., \& Hekkert, P. (1999). Common unconscious dynamics underlie uncommon conscious effects: A case study in the interaction of perception and creation. In J. Jordan (Ed.), Modeling consciousness across the disciplines (pp. 179-218). Lanham, MD: University Press.

Velleman, D. (1997). How to share an intention. Philosophy and Phenomenological Research, 57, 29-50.

Wainwright, R., \& Baker, J. (2006). Farewell to a larrikin adventurer. The Sydney Morning Herald. Available from http://www.smh.com.au/ news/national/farewell-to-a-larrikin- adventurer-killed-in-his-prime/ 2006/09/04/1157222072696.html.

Walther, E., Bless, H., Strack, F., Rackstraw, P., Wagner, D., \& Werth, L. (2002). Conformity effects in memory as a function of group size, dissenters, and uncertainty. Applied Cognitive Psychology, 16, 793-810.

Wegner, D. M. (1987). Transactive memory: A contemporary analysis of group mind. In B. Mullen \& G. R. Goethals (Eds.), Theories of group behavior Springer Series of Social Psychology (pp. 185-208). NY: Springer-Verlag.

Wegner, D. M., Erber, R., \& Raymond, P. (1991). Transactive memory in close relationships. Journal of Personality and Social Psychology, 61, 923-929. 
Wegner, D. M., Giuliano, T., \& Hertel, P. T. (1985). Cognitive interdependence in close relationships. In W. Ickes (Ed.), Compatible and incompatible relationships Springer Series of Social Psychology (pp. 253-276). NY: Springer-Verlag.

Weldon, M. S., \& Bellinger, K. D. (1997). Collective memory: Collaborative and individual processes in remembering. Journal of Experimental Psychology: eLearning, Memory and Cognition, 23, 1160-1175.

Wertsch, J. V. (2002). Voices of collective remembering. Cambridge: Cambridge University Press.

Williams, D., \& Hearn, L. (2006). Steve Irwin killed by a stingray. The Sydney Morning Herald. Available from http://www.smh.com.au/ news/national/steve-irwin-killed-by-stingray/2006/09/04/ 1157222051512.html.

Wilson, R. A. (1994). Wide computationalism. Mind, 103, 351-372.

Wilson, R. A. (1995). Cartesian psychology and physical minds: Individualism and the sciences of the mind. New York: Cambridge University Press.

Wilson, R. A. (2004). Boundaries of the mind: The individual in the fragile sciences: Cognition. Cambridge, UK: Cambridge University Press.

Wilson, R. A. (2005a). Collective memory, group minds, and the extended mind thesis. Cognitive Processing, 6, 227-236.
Wilson, R. A. (2005b). Genes and the agents of life. New York: Cambridge University Press.

Wilson, R. A. (2007). Levels of selection. In M. Matthen \& C. Stephens (Eds.). Handbook of the philosophy of science: Philosophy of biology (Vol. 3). New York: Elsevier.

Wilson, R. A., \& Clark. A. (in press). How to situate cognition: Letting nature take its course. In M. Aydede \& P. Robbins (Eds.), The Cambridge handbook of situated cognition. Cambridge: Cambridge University Press.

Wilson, R. A., \& Keil, F. C. (2000). The shadows and shallows of explanation. Minds and Machines, 8, 137-159 [Modified version reprinted in Keil, F. C., \& Wilson, R. A. Explanation and cognition. Cambridge, MA: MIT Press].

Wimsatt, W. C. (1986). Forms of aggregativity. In A. Donagan \& M. A. Wedin (Eds.), Human nature and natural knowledge (pp. 259-291). Dordrecht: Reidel.

Wright, D. B., \& Klummp, A. (2004). Collaborative inhibition is due to the product, not the process, of recalling in groups. Psychonomic Bulletin and Review, 11, 1080-1083.

Yaron-Antar, A., \& Nachson, I. (2006). Collaborative remembering of emotional events: The case of Rabin's assassination. Memory, 14, $46-56$. 